\title{
THE
}

\section{Improving Students' Data Analysis and Presentation Skills: The Ocean State Circuits, Inc. Forecasting Project}

James R. Kroes

Yuwen Chen

University of Rhode Island, yuwen@uri.edu

Paul Mangiameli

University of Rhode Island, mangia@uri.edu

Follow this and additional works at: https://digitalcommons.uri.edu/cba_facpubs

The University of Rhode Island Faculty have made this article openly available.

Please let us know how Open Access to this research benefits you.

This is a pre-publication author manuscript of the final, published article.

Terms of Use

This article is made available under the terms and conditions applicable towards Open Access

Policy Articles, as set forth in our Terms of Use.

Citation/Publisher Attribution

Kroes, James R.; Chen, Yuwen; and Mangiameli, Paul. (2013). "Improving Students' Data Analysis and Presentation Skills: The Ocean State Circuits, Inc. Forecasting Project". Decision Sciences Journal of Innovative Education, 11(2), 165-174. http://dx.doi.org/10.1111/dsji.12004 


\title{
Improving Students' Data Analysis and Presentation Skills: The Ocean State Circuits, Inc. Forecasting Project
}

\author{
by \\ James R. Kroes (e-mail: jimkroes@boisestate.edu) \\ Supply Chain Management, College of Business and Economics, \\ Boise State University, \\ 1910 University Drive, Boise, ID 83725 \\ Yuwen Chen (e-mail: yuwen@mail.uri.edu) \\ Paul Mangiameli (e-mail: mangia@mail.uri.edu) \\ Supply Chain Management, College of Business Administration \\ University of Rhode Island, \\ Administration, 7 Lippitt Road, Kingston, RI 02881
}




\begin{abstract}
Many potential employers expect that newly hired students will arrive on-the-job with the ability to analyze data, utilize spreadsheets, and communicate findings and recommendations. We designed the Ocean State Circuits, Inc. Forecasting Project to address these gaps in our students' knowledge of analytical tools (such as the vlookup() function and pivot tables), their ability to write mathematical formulas in a spreadsheet, their understanding of more advanced data analysis features (e.g. regression, correlation), and their ability to communicate and present managerial conclusions. The exercise requires student teams to act as "consultants" and utilize spreadsheets to analyze and forecast the demand for a hypothetical set of products and then communicate their findings to "management" in a professionally formatted report document. A survey of students that have completed the exercise indicates that their knowledge level of the tools used in the project increased significantly from before to after they completed the case. Similarly, anecdotal feedback from employers has suggests that students that have completed the exercise seem more capable of dissecting data when investigating business issues.
\end{abstract}




\section{INTRODUCTION}

"Your students don't have good analytical skills." - Hiring Manager

"Nowadays, college kids can't present data well." - Supply Chain Executive

What business professors have not heard comments such as these about our students? Strive as we might to address these issues, we keep hearing the same criticisms. Often, though, these criticisms are generalizations that derive from a lack of specific skills rather than a general lack of knowledge on the part of our students. Many potential employers expect that newly hired students will arrive on-the-job with definite skills required to analyze data and to communicate their findings and recommendations. Often, these analytical skills require knowledge of particular spreadsheet functions.

In order to understand the specific employer expectations and shortcomings they have experienced from former students that they have hired, we initiated conversations with potential employers, newly employed former students, and current students seeking positions. From these conversations, we learned that students are expected to have a working knowledge of data manipulation tools (such as the vlookup() function and pivot tables), the ability to write mathematical formulas in a spreadsheet, an understanding of more advanced data analysis features (e.g. regression, correlation), and the softer skills needed to create tables and graphs to communicate findings. Further, we assessed our courses and found that while students learn about a number of useful analytical tools and presentation skills across classes, they typically don't reapply them in other classes (i.e. it is rare for them to be required to complete comprehensive assignments that utilize tools and skills learned across multiple classes). To 
address these shortcomings, we developed an exercise that requires students to utilize Microsoft Excel spreadsheets to analyze and forecast the demand for a hypothetical set of products and then to communicate their findings in a professional manner. The exercise was implemented within the forecasting section of a junior-level operations and supply chain course that all business students are required to complete.

\section{EXERCISE GOALS}

The purpose of our exercise is to increase the ability of our students to analyze data and present their findings. Specifically, students need a working knowledge of Excel based data manipulation tools including the ability to write mathematical formulas in a spreadsheet, an understanding of more advanced data analysis features (e.g. regression), and the skills to create tables and graphs. Additionally, the exercise is designed to reinforce students' understanding of demand management by requiring them to derive meaningful managerial conclusions given a set of demand data. Finally, the exercise requires the students to submit a professionally formatted report communicating their analytical findings in order to improve their ability to transform quantitative results into managerially relevant recommendations.

\section{THEORETICAL FOUNDATIONS}

Forecasting was chosen as the underlying theme of this exercise because, as expressed by Albritton and McMullen (2006), it is “...one area where management science techniques facilitate enhanced decision making..., which directly impacts many functional areas of business." We designed this exercise to mimic an actual business case in an effort to show students the value that statistics will play in their future careers, as student enjoyment has been positively associated with the students' perceived value of statistics education (Cybinski and Selvanathan, 2005). In our review of previous techniques used to improve students' 
comprehension of forecasting, we found that Gavorneni (2008) utilizes a university's basketball scores in an in-class exercise which allows students to gain practical experience with forecasting. We decided to use a complimentary approach to Gavorneni's exercise, by developing an out-ofclass exercise that requires student teams to apply the concepts learned in-class to create and analyze a variety of forecasts.

In addition, we wanted our exercise to develop our students' spreadsheet analysis skills. There are several ways of teaching business students spreadsheet skills. Some schools (for example, Carleton College) provide MS Excel tutorials online that students complete individually for credit. Lehigh University has a MS Excel Competency Program and requires its College of Business and Economics students to pass a proficiency exam. More recently, a number of management science courses are taught using Excel-based textbooks (Ragsdale, 2001; Ragsdale 2010; Winston and Albright, 2011). Constrained with our curriculum, course structure, and resources, we chose a problem based learning approach. As suggested by Mykytyn, Pearson, Paul, and Mykytyn (2008), we felt that a problem-based learning approach would reinforce and illustrate the textbook readings and classroom lectures on forecasting.

Our exercise is structured as a simulated business case study because, as Meyers and Jones (1993) point out, case studies can facilitate active learning and improve problem-solving skills. For the purposes of this exercise, we employed an outside-the-classroom active learning approach. Several previous studies utilize semester-long active learning projects to improve students' understanding of operations management concepts. Heriot, Cook, Jones, and Simpson (2008) use this approach for student consulting projects in an effort to enhance the real-world relevance of a core Productions and Operations Management course. In "Teaching Six Sigma to Undergrads: A Simplified Real Project Approach" Zuckweiler (2011) describes a team based, 
active learning, semester long project in which most of the project work was done outside the classroom. In the reported results of Zuckweiler's exercise, both the learning outcomes and student satisfaction (assessed using student evaluations) were found to be very positive. For our exercise, we chose to adopt a shorter-term project closer to the approach used by Fuller and Bradbard (2009). They used two class periods for instructions on their project (we used one) and gave students approximately three weeks to complete the project. In both their exercise and ours, the student teams meet mostly outside of class to complete their work.

\section{EXERCISE OVERVIEW}

The exercise requires student teams to analyze a dataset and then summarize their findings in a professionally formatted report that is delivered to "Management" (i.e. - the course instructor). After teaching that part of the course devoted to demand management (usually this module is taught early in the course), the instructor takes one class period to describe the project. The assignment is then due approximately in two to three weeks from that point. All team meetings occur outside of the formal class structure. In keeping with the active learning, out-ofclass approach, we created a tutorial video and accompanying practice dataset that allows students to run-through the functions and tools that they will use to complete the assignment. The tutorial and practice data, as well as the detailed exercise instructions and a sample of the project data are available at https://sites.google.com/site/oceanstatecircuits/. To streamline the grading process, we have created a master file that uses Visual Basic code to generate ten unique data sets and the associated solutions. The master file is available to verified professors upon email request.

The exercise places teams of students into the role of business consultants working to improve the forecasting methods for computer circuit components at a hypothetical electronics 
company: Ocean State Circuits, Inc. Each team is given historical demand then asked to use Microsoft Excel to prepare the data, analyze the data, and create forecasts. We created an Excel Visual Basic program to generate monthly demand data for four products incorporating four unique demand patterns. The program includes a randomization feature that creates ten unique sets of demand data, one for each student team (we typically have classes of 40 students that are divided into groups of four). Although the randomizer makes each team's data set different, we incorporate specific demand patterns into each of the four product's data: the SDD-100 Chip exhibits average demand over the three years, the XJ-422 Relay has a steady trend (randomly alternating between increasing in some datasets and decreasing others), the TM-1000X Board has a seasonal demand pattern and the SSD-2200 Chip exhibits a slight decline in sales in the first 18 months followed by a slight increase over the last 18 months.

The demand data is stored in an Excel worksheet consisting of 144 records. Each record includes the month (1 to 36), the year, the season (winter, spring, summer, autumn), the monthly unit demand, and the product ID number (1 to 4 ). The worksheet also includes a reference table that includes the product ID number, the product name, and the unit sales price for each of the four products.

At the start of the exercise, each team is given a set of written instructions describing each of the assignment's tasks. The instructions include samples of the tables and graphs that the students will need to create. The exercise is divided into five distinct tasks:

\section{Task 1 - Complete the Dataset}

Students must prepare their data before they can begin analyzing it and preparing forecasts. The demand data does not include the product names or monthly revenue totals; which the students will need in later tasks. To complete this task, the teams must first use the vlookup() 
function to associate the actual product name (from the lookup table) with the Product ID \# included in the data. Next, the students need to write a formula that computes the monthly revenue for each product by using vlookup() to find the per unit revenue for each product and then multiplying that by the monthly unit demand.

\section{Task 2 - Visually Analyze the Demand}

In this task, the students are required to use the Excel pivot table functionality to create a demand summary pivot table report and chart for the four products. The pivot table includes a column for each of the four products and 36 rows (for each month of data) listing the monthly sales in units for each product. This table is used to create a chart of the demand (see Figure 1 for a sample chart) that the students visually inspect in order to answer several questions about the product demand patterns.

\section{$<$ Insert FIGURE 1 approximately here.>}

\section{Task 3 - Seasonality Analysis}

Task 3 requires the students to construct a slightly more complex pivot table that summarizes each product's sales revenue by year and season (an example table is provided in Figure 2). The students are then asked to identify which product(s) exhibit seasonality and to discuss their strategy for dealing with the seasonality when forecasting.

<Insert FIGURE 2 approximately here.>

\section{Task 4 - Regression and Moving Average Forecasting}

In Task 4, the students use the 36 months of demand data for the XJ-422 Relay to compare the accuracy of a regression forecast with a three-period moving average forecast. The students create the two forecasts for the last 12 months and then calculate the Mean Absolute Deviation and Mean Squared Error for both forecasting methods. The students are asked to 
recommend which forecasting method is more accurate for this product. Although the students are permitted to use Excel's built in regression functionality, they must program the moving average, MAD, and MSE calculations manually.

\section{Task 5 - Exponential Smoothing Forecasting}

Task 5 requires students to create two exponential smoothing forecasts for the SSD-220 Chip, using two smoothing constant (i.e. $\alpha$ ) values of 0.2 and 0.6 . The students are also asked to prepare a graph of the actual demand and both forecasts (Figure 3). Finally, the students compute the MAD and MSE values for the last 12 months for both forecasts and justify their recommendation of which value of $\alpha$ produces a more accurate forecast. <Insert FIGURE 3approximately here.>

\section{Reporting the Findings and Recommendations}

After completing the five tasks, each student team is required to summarize their findings in a professionally formatted printed report. The submitted reports should be written as a single document with consistent fonts, headings, spacing, etc. Written responses and recommendations are required to use concise language and proper grammar. Figures and tables are required to be incorporated into the report and discussed in the body of the document. The professionalism of the case report typically accounts for $30 \%$ of the project's overall grade.

\section{RESULTS}

The exercise was presented over a three year period in multiple course sections taught by various instructors in the introductory (junior-level) course in operations and supply chain management. We surveyed 415 students from multiple class sections and institutions to garner feedback on the effectiveness of the case. A uniform survey instrument was designed and administered to all sections of students that completed the exercise (before the graded assignments were returned to 
them). Each student self-assessed their pre- and post-exercise ability to use the tools required by the exercise. To assess the significance of the changes in their skill levels from before to after completion of the exercise, we conducted a paired-sample t-test of the student responses. The results of the t-tests (detailed in Table 1) show that the students' knowledge level for each of the tools increased significantly $(\mathrm{P}<0.001)$ after they completed the case. The results also show that the variation between students' skill levels decreased, which demonstrates a more consistent level of knowledge across our students. This improved consistency will hopefully allow employers to better predict the skills that newly hired students will have when they arrive on the job.

<Insert TABLE 1 approximately here.>

Student teams have indicated that they typically spend between six to ten hours completing the project (split amongst the team members). The variance between the amounts of time required for teams to complete the project seems to be dependent on team members' prior knowledge of Excel and the teams' level of effort invested in professionally formatting the final report. From Table 2, which shows the results of the students' overall impressions about the case, we see that the tutorial was well regarded and the case compared favorably with other team assignments and the overall level of enjoyment was slightly above average.

In the time since the exercise was initially developed, we have continued to engage former students and employers to determine if our students are better prepared for the analytical challenges they face as they enter the business world. Anecdotally, we have had a number of former students indicate that they felt that the exercise enhanced their base set of spreadsheet skills and their ability to analyze data. Several students have shown potential employers their final reports from this exercise during actual interviews when asked to discuss their ability to 
analyze data. Similarly, feedback from employers has been positive. Several employers that have hired students repeatedly over the past several years have commented that our more recent students do seem more capable of dissecting data when investigating business issues. One particular hiring manager, whose comments in part motivated the creation of this exercise, now specifically asks students about their experience with the Ocean State Circuits exercise during interviews.

$<$ Insert TABLE 2 approximately here.>

\section{CONCLUSION}

The Ocean State Circuits project uses an outside the classroom active learning approach to fill a gap in our students' analytical skill sets. The results have been very positive: students learned from the on-line tutorials and applied that knowledge to the project. The project itself was well received with students evidencing strong learning values from the exercise. Colloquially collected information from employers of recent graduates indicated that our students did, indeed, have stronger analytic and presentation skills once we began teaching with Ocean State Circuits, Inc. 


\section{REFERENCES}

Albritton, M.D. and McMullen, P.R. (2006). Classroom Integration of Statistics and Management Science via Forecasting. Decision Sciences Journal of Innovative Education, 4(2), 331-336.

Cybinski, P. and Selvanathan, S. (2005). Learning Experience and Learning Effectiveness in Undergraduate Statistics: Modeling Performance in Traditional and Flexible Learning Environments. Decision Sciences Journal of Innovative Education, 3(2), 251-271.

Fuller, B.K. and Bradbard, D.A. (2009). An Entrepreneurial Application of a Geographic Information System. Decision Sciences Journal of Innovative Education, 7(1), 163-170.

Gavirneni, S. (2008). Teaching the Subjective Aspect of Forecasting Through the Use of Basketball Scores. Decision Sciences Journal of Innovative Education, 6 (1), 187-195.

Heriot, K.C., Cook, R., Jones, R.C. and Simpson, L. (2008). The Use of Student Consulting Projects as an Active Learning Pedagogy: A Case Study in a Production/Operations Management Course. Decision Sciences Journal of Innovative Education, 6(2), 463-481.

Meyers, C., \& Jones, T. B. (1993). Promoting active learning. Jossey-Bass, San Francisco, CA. Mykytyn, K., Pearson, A., Paul, S. and Mykytyn, Jr., P.P. (2008).The Use of Problem-Based Learning to Enhance MIS Education. Decision Sciences Journal of Innovative Education, $6(1), 89-114$.

Ragsdale, C. T. (2001). Teaching Management Science With Spreadsheets: From Decision Models to Decision Support. Transactions on education, 1(2), 68-74.

Ragsdale, C. T. (2010) Spreadsheet Modeling \& Decision Analysis: A Practical Introduction to Management Science, 6th edition. South-Western College Publishing. 
Winston, W. L. and S. C. Albright. (2011) Practical Management Science, 4th edition. SouthWestern College Publishing.

Zuckweiler, K.M. (2011). Teaching Six Sigma to Undergrads: A Simplified Real Project Approach. Decision Sciences Journal of Innovative Education, 9(1), 137-142. 
Figure 1: Sample of the Pivot Table demand chart created in Task 2.

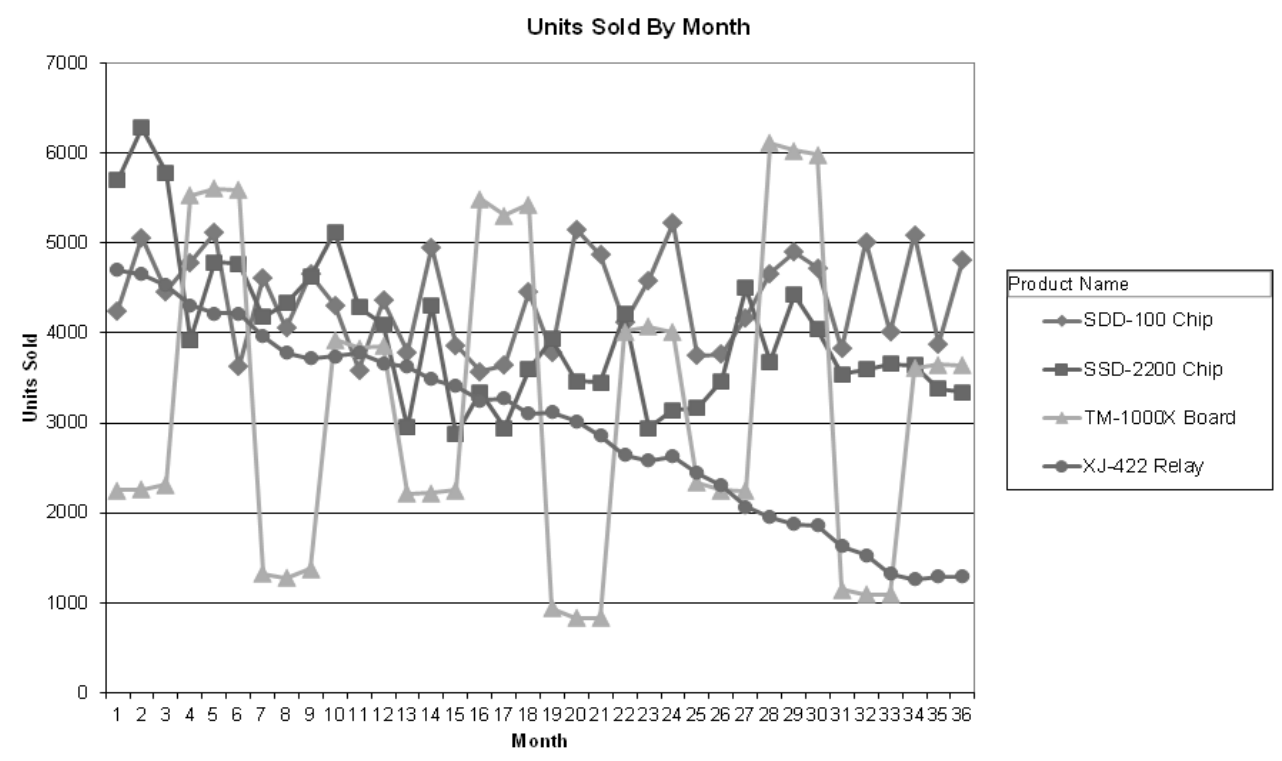

Figure 2: Sample of a Seasonal Pivot Table demand chart created for one product in Task 3.

\begin{tabular}{|l|l|rrr|r|}
\hline \multicolumn{2}{l|}{ Sum of Sales Revenue } & \multicolumn{4}{l|}{ Year } \\
\hline Product Name & Season & $\mathbf{2 0 0 7}$ & $\mathbf{2 0 0 8}$ & $\mathbf{2 0 0 9}$ & Grand Total \\
\hline TM-1000X Board & 1: Winter & $\$ 819,600$ & $\$ 802,680$ & $\$ 820,560$ & $\$ 2,442,840$ \\
& 2: Spring & $\$ 2,007,720$ & $\$ 1,947,720$ & $\$ 2,174,880$ & $\$ 6,130,320$ \\
& 3: Summer & $\$ 478,560$ & $\$ 312,480$ & $\$ 401,160$ & $\$ 1,192,200$ \\
& 4 : Autumn & $\$ 1,393,440$ & $\$ 1,451,520$ & $\$ 1,309,320$ & $\$ 4,154,280$ \\
\hline
\end{tabular}

Figure 3: Sample of a Demand and Forecast Chart created for the SSD-220 product. 


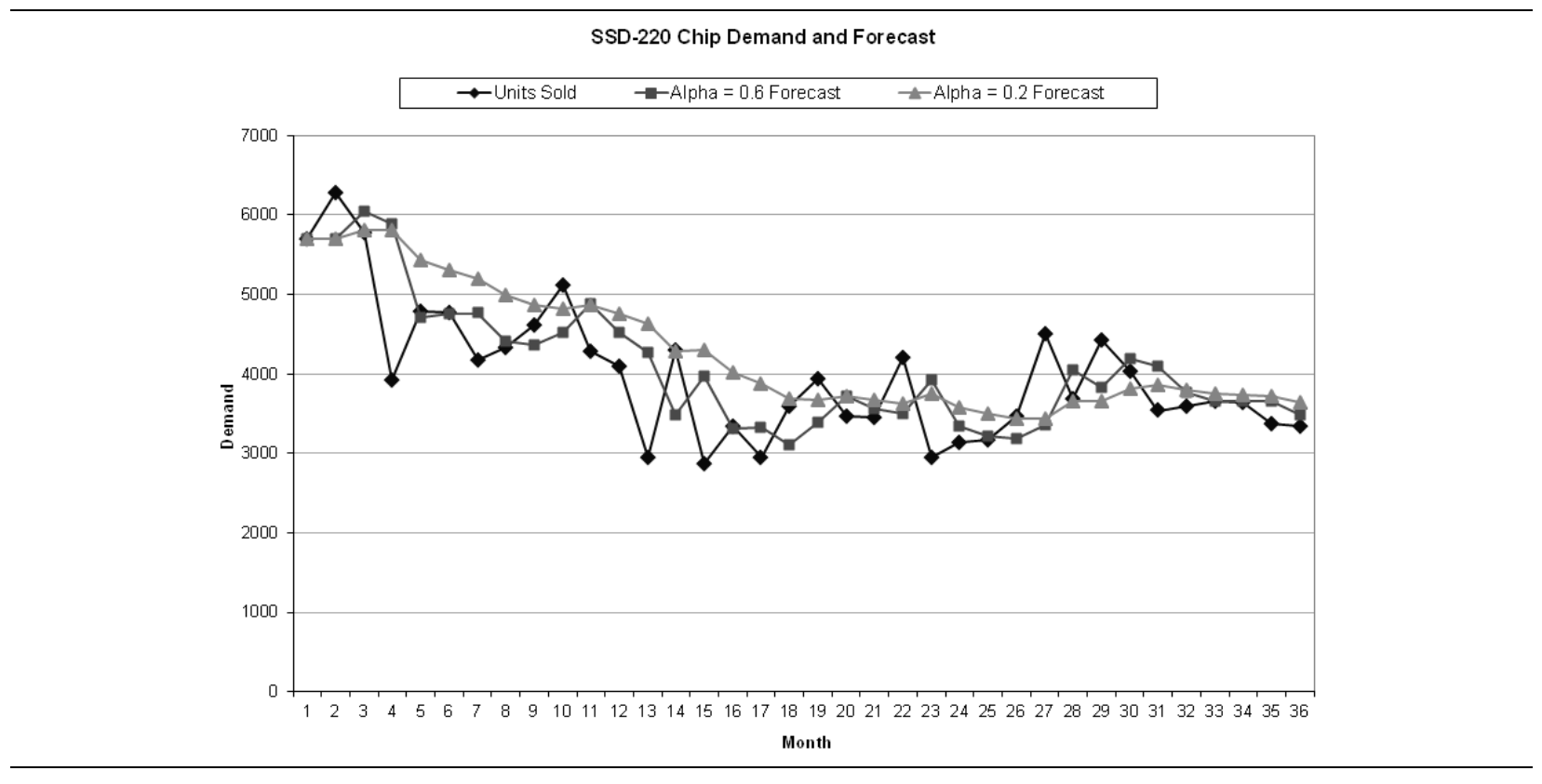


Table 1: Students Pre- and Post-Exercise Subject Matter Knowledge.

\begin{tabular}{|c|c|c|c|}
\hline Subject Matter Knowledge & $\begin{array}{c}\text { Before } \\
\text { Assignment } \\
\text { (Std. Dev.) }\end{array}$ & $\begin{array}{c}\text { After } \\
\text { Assignment } \\
\text { (Std. Dev.) }\end{array}$ & $\begin{array}{c}\text { Change } \\
\text { from } \\
\text { Before to } \\
\text { After }\end{array}$ \\
\hline Application of the vlookup() function & $\begin{array}{c}2.8 \\
(1.7)\end{array}$ & $\begin{array}{c}5.6 \\
(1.1)\end{array}$ & $\begin{array}{l}+2.8^{*} \\
(-0.6)\end{array}$ \\
\hline Application of Pivot Tables & $\begin{array}{c}2.4 \\
(1.8)\end{array}$ & $\begin{array}{c}5.4 \\
(1.1)\end{array}$ & $\begin{array}{l}+3.0 * \\
(-0.7)\end{array}$ \\
\hline Interpreting Data Graphically & $\begin{array}{c}4.8 \\
(1.5)\end{array}$ & $\begin{array}{c}6.1 \\
(0.8)\end{array}$ & $\begin{array}{l}+1.3^{*} \\
(-0.7)\end{array}$ \\
\hline Time Series Forecasting & $\begin{array}{c}3.2 \\
(1.7)\end{array}$ & $\begin{array}{c}5.5 \\
(1.0)\end{array}$ & $\begin{array}{l}+2.3 * \\
(-0.7)\end{array}$ \\
\hline
\end{tabular}

$\mathrm{n}=415$ students

* indicates that the change from Before Assignment to After Assignment is significant at the $\mathrm{p}<0.001$ level based on a paired sample t-test.

Note: Student self-evaluation of knowledge level was assessed using a 7-point Likert Scale, ranging from: 1 = "Low Level of Knowledge" to 7 = "High Level of Knowledge"

Table 2: Student Evaluation of Ocean State Circuits

\begin{tabular}{|c|c|}
\hline Assignment Evaluation Questions & $\begin{array}{c}\text { Average } \\
\text { Rating } \\
\text { (Std. Dev.) }\end{array}$ \\
\hline $\begin{array}{l}\text { How would you rate the on-line teaching tutorial } \\
\text { provided for this case assignment? } \\
(1=\text { "Very Bad" to } 7 \text { = "Excellent") }\end{array}$ & $\begin{array}{c}5.9 \\
(0.8)\end{array}$ \\
\hline $\begin{array}{l}\text { How would you rate the level of enjoyment from } \\
\text { the Ocean State Circuit case assignment? } \\
\text { ( } 1 \text { = "Enjoyed Very Little" to } 7 \text { = "Enjoyed A Lot") }\end{array}$ & $\begin{array}{c}4.2 \\
(1.6)\end{array}$ \\
\hline $\begin{array}{l}\text { Compared to other team assignments how would } \\
\text { you overall rate the Ocean State Circuit case } \\
\text { assignment? } \\
\text { ( } 1=\text { "One of the Worst" to } 7=\text { "One of the Best") }\end{array}$ & $\begin{array}{c}5.1 \\
(1.1)\end{array}$ \\
\hline
\end{tabular}

